\title{
Reflective Practice in Action: A Case Study of a Writing Teacher's Reflections on Practice
}

Thomas S.C. Farrell

Reflective practice, a popular item in current second-language teacher education and development programs, can help bridge the gap between a teacher's beliefs and classroom practices. This article outlines a case study, highlighting how one teacher of academic writing initiated the exploration of her teaching and how she used classroom observations and oral recall to help her reflect on her practice. Specifically, the exploration sought to outline the teacher's beliefs about, and classroom practices in, teaching academic writing. It is suggested that oral recall and classroom observations may be effective methods for helping language teachers discover the relationship between their beliefs and classroom practices.

La pratique réflexive constitue un élément actuellement à la mode dans les programmes de formation et de développement des enseignants. Elle peut aider à faire le pont entre les croyances d'un enseignant et ses pratiques en salle de classe. Cet article porte sur une étude de cas et la façon dont une enseignante de rédaction académique a initié sa réflexion sur sa pratique en se penchant sur son utilisation d'observations dans la classe et d'évocations verbales. Nous proposons que les évocations verbales et les observations dans la classe puissent constituer pour les enseignants des outils efficaces dans leur découverte du rapport entre leurs croyances et leurs pratiques en salle de classe.

\section{Introduction}

The old cliché "Experience is the greatest teacher" may not be as true as we think, for we do not learn as much from experience as we learn from reflecting on that experience. In studies of teacher practices, Cruickshank and Applegate (1981) characterize reflection as a process that helps "teachers to think about what happened, why it happened, and what else could have been done to reach their goals" (p. 553). Although not specifically stated, this idea of reflection also encompasses teachers examining their underlying assumptions and beliefs about teaching and learning.

In the field of second-language teaching, there has been a growing awareness of the need to understand and account for the underlying belief systems of experienced language teachers because these may help us to understand varying attitudes toward teaching in second-language classrooms (Borg, 
1998, 2003; Burns 1992; Golombek, 1998). Results from this type of research (Johnson, 1990; Burns) have indicated that a gap may exist between what teachers believe they do in the classroom (beliefs) and what they actually do (actions). One way of exposing gaps between teacher beliefs and actual classroom practice is to encourage teachers to engage in reflective practice (Farrell, 2004). Valli (1997) has suggested that reflective teachers "can look back on events, make judgments about them, and alter their teaching behaviors in light of craft, research, and ethical knowledge" (p. 70). Thus reflective teachers are proactive decision-makers who take more control of their classrooms by being, as Nieto, Gordon, and Yearwood (2002) point out, "transformative intellectuals" (p. 345).

This article outlines a case study of the reflections of one experienced English-for-academic-purposes (EAP) teacher, Chee (a pseudonym), in the context of Singapore. Not many case studies exist (and none about teachers of academic writing in the Asia-Pacific region) on how experienced EAP teachers reflect on their work. This study is also unique in that the EAP teacher initiated this exploration of her practice by inviting me (she was aware that I was researching the area of reflective practice) to observe her academic writing classes; saying, "I want to have an observer's perception and interpretation of these academic writing classes." I accepted this invitation in order to learn more about how to promote reflective practice with experienced EAP writing teachers.

For the purposes of this exploration, I refer to the term belief as the articulated underlying rationale that guided and influenced Chee's decisionmaking in teaching academic writing, and the term practice refers to Chee's observed classroom practices including the various activities and procedures and the instructional strategies she used.

\section{Reflective Practice}

Reflective practice requires that teachers examine their values and beliefs about teaching and learning so that they can take more responsibility for their classroom actions (Farrell, 2004). In order to engage in reflective practice, teachers must move beyond mere contemplations of teaching (Wallace, 1998); reflecting on practice is a systematic and methodological process (Farrell). In this way, teachers can begin to examine their attitudes, assumptions, and beliefs about language learning and teaching, thus being better positioned to make critically reflective decisions about their teaching (Richards \& Lockhart, 1994). Richards and Lockhart suggest that this type of systematic reflection is necessary because "teachers are often unaware of what they do when they teach" (p. 3).

Concurrent with increased levels of interest in reflective practice in second-language teaching is growing attention of the awareness of teaching as a thinking activity (Borg, 2003; Richards \& Farrell, 2005). Teaching as 
thinking asks how teachers conceptualize their work and looks at the kinds of thinking and decision-making that underlies their practice (Richards, 1994; Richards \& Farrell). As a result of these two concepts in second-language teaching, the acquisition of teaching expertise (Tsui, 2003) is seen as process that involves teachers actively constructing personal and workable theories of teaching by, among other things, reflecting on their belief systems and looking at how these beliefs are translated (or not) into actual classroom practice.

Teacher beliefs, defined by Kagan (1992) as "unconsciously held assumptions about students, classrooms, and the academic material to be taught" (p. 65), are developed over a teacher's career and often held tacitly. Teacher beliefs are important because they are said to influence how teachers teach; however, teachers do not usually articulate their teaching beliefs to themselves or to others and are therefore not aware of their influence on their teaching. This is especially important if there is any discrepancy between what say they believe (their theory of teaching) and their actual classroom practice (their theories-in-action). As Woods (1996) suggests, teachers must be on guard against "claim[ing] allegiance to beliefs consistent with what they perceive as the current teaching paradigm rather than consistent with their unmonitored beliefs and their behaviour in class" (p. 71). By engaging in reflective practice, language teachers can look for any inconsistencies between beliefs and practices.

A number of studies relevant to this research have investigated the extent to which experienced writing teachers' beliefs affect their classroom practices: Shi and Cumming's (1995) case study of the conceptions of five teachers of second-language writing, Pennington et al.'s (1997) Asia-Pacific study of teachers of composition, and Lee's (1998) Hong Kong study of writing teachers. Shi and Cumming interviewed five experienced teachers of second-language writing, discovering that each of them conceptualized their work from different perspectives even though each teacher had graduated from the same university and had taught in the same ESL program. Shi and Cumming's findings are important because they suggest that "knowledge guiding second-language writing instruction needs to be considered largely in personal, practical terms," and that acknowledging this personal conceptualization of second-language writing teachers' work is "vital in considering initiatives for curriculum change in the domain of second language writing" because teachers may or may not accept curriculum changes depending on their fit with their personal beliefs, which are "founded on years of previous experience, reflection, and information" (p. 104).

In an Asia-Pacific-wide study of writing teachers, which included native and non-native teachers, Pennington et al. (1997) reported that a gap existed between ideal perceptions of teaching and actual teaching situations, mainly because the "constraints of the educational system" (p. 131) caused these 
gaps. Pennington et al. suggest that writing teachers in the Asia-Pacific region are adapting and adjusting the "process approach" to writing to suit their individual circumstances. Rather than voicing concerns with these adaptations, Pennington et al. say they are "healthy and realistic" adaptations and have been "formed as deliberate or unconscious syntheses of process and product elements" (p. 140).

In addition, a study conducted by Lee (1998) discussed the existence of a similar gap between teachers' beliefs about the teaching of second-language writing and their actual classroom practices in Hong Kong (again, as reported in questionnaires and some follow-up interviews). The 10 Hong Kong secondary school teachers in the study initially stated that they believed that textual coherence was more important than grammar and vocabulary in writing, writing instruction, and writing assessment. However, Lee pointed out that such a belief was "not translated in their own practice" (p. 67). It seems that these same teachers were more concerned with grammar and vocabulary while teaching ESL writing.

\section{Methodology}

Qualitative research procedures were used in the collection and analysis of the data in this case study (Bogdan \& Bilken, 1982; Glesne \& Peshkin, 1992). Earlier studies primarily used questionnaires to collect data (although Pennington et al., 1997, also included some classroom observations), and investigated teachers' perceptions of what they do. Although the case study discussed in this article seeks to complement this existing literature on the beliefs and practices of second-language writing teachers, it uses a different methodology, that of the use of oral recall, oral commentary, reflective writing, and classroom observations as the primary means of data collection. With this approach, the emphasis in collection and analysis of data of Chee's postinteractive reflections is on understanding and interpretation, as she attempted to rationalize her practical knowledge after the teaching event, and then consider her plans for future actions (Lowych, 1986; Shi \& Cumming, 1995).

\section{Context}

Chee, a female experienced ESL and EFL teacher, holds an MA degree in applied linguistics and has nearly 20 years of teaching experience. At the time of the study she was teaching academic writing in an intensive English program for scholars from the People's Republic of China at the National Institute of Education in Singapore. These scholars are in preparation to enter the university system in Singapore and all use English as their foreign language. We agreed that although I would act as facilitator for Chee by recommending and organizing opportunities for her to reflect and to "manage" the 
overall process of the project, Chee herself would have control of the direction and duration of the reflective process.

\section{Data Collection}

Data were collected by means of classroom observations, reflective journalwriting, and conversations (rather than formal interviews), both face-to-face conversations and "conversations" conducted on electronic mail, where topics were discussed when raised by Chee rather than myself. We agreed that classroom observations and reflective journal-writing would be conducted in order to gain insight into how Chee interpreted the events of her writing classes. Classroom observation was an important aspect of the reflective process because, as Gaies (1991) has pointed out, "What we see, when we observe teachers and learners in action, is not the mechanical application of methods and techniques, but rather a reflection of how teachers have interpreted these things" (p. 14).

In total, seven classes were observed (each class lasted two hours and was videotaped and later transcribed) as suggested by Chee. Chee outlined the classes I observed as follows: the first three pre-writing activity classes; the fourth, a peer-response class; the fifth class, for writing and typing the first draft of the essay; and the sixth class, which was for revising her students' first draft. According to Chee, this series of classes constituted one cycle of writing in her approach to the teaching of academic writing; she remarked, "One complete cycle of writing stretches from drafting to finished product." Chee also asked me to observe a seventh class that started a new cycle of writing. For this class she asked me to note "any changes you see from the first cycle" [of six classes]. Chee agreed to keep a journal in which to reflect on whatever and whenever she wanted. However, she said that she would write after every observation to note her own perceptions of the classes I would observe. I also kept a reflective journal (Glesne \& Peshkin, 1992; Lincoln \& Guba, 1985) to record classroom events and the conversations (oral and e-mail) with Chee. Most of the conversations I had with Chee were also audiotaped and later transcribed.

\section{Data Analysis}

Data analysis consisted of scanning the data after transcribing and coding relevant sections of the conversations and e-mail discussions in order to look for patterns and themes (Bogdan \& Biklen, 1982). The discussions, journal entries, and classroom observations were coded by inductive analysis procedures (Johnson, 1992). In order to establish the trustworthiness of the findings, the quality of the data were assessed by checking for "credibility, transferability, and dependability" (Lincoln \& Guba, 1985, p. 300). Lincoln and Guba suggest that the technique of triangulation will improve the probability that the findings and interpretations will be credible. Stake (1995) 
argues that triangulation can be achieved with "multiple approaches within a single study" (p. 114). Thus I collected data by audio-recordings (later transcribed) of each conversation with Chee, and I also wrote extensive field notes (later written up in a more detailed log) during and after each event. Chee also wrote regular journal entries. In addition, the teacher read and authenticated my interpretations of the findings. This form of member checking (Lincoln \& Guba) occurred twice in this study: first, after all the data had been analyzed and a draft written; second, when the "final" version of this article had been written.

To help me (observer) further analyze the classroom interaction, I conducted a seating chart observation record (SCORE) analysis of representative sections of these classroom lessons. Day (1990) has noted that the SCORE instrument is useful to look at "teacher and student talk; at task; and movement patterns" (p. 51). The SCORE instrument was useful for both of us to verify communication that occurred in Chee's classes.

\section{Findings}

In this section, I first outline Chee's stated beliefs about teaching EAP writing. This is then followed by details from the observations of Chee's writing classes.

\section{Chee's Stated Beliefs}

In the conversations and in subsequent e-mail communications, many of them before the classroom observations, Chee reveled many of her beliefs about teaching academic writing. She stated that many of her beliefs had been built up over many years teaching in varying contexts, namely, while teaching in Malaysia and teaching as a student in the United States. Chee believes the act of writing involves some kind of process and that it takes time to produce, in Chee's words: "Writing is an intellectual activity which takes a lot of time for thinking and analyzing." Although she says that she takes a process approach to teaching writing, she has also made her own interpretations about how to apply this approach to writing: "I want my students to understand the processes involved in writing a good composition, as opposed to focusing only on the final product in writing." She says that this involves getting the students "to understand the different stages a composition goes through from brainstorming to planning, drafting, peerconferencing/peer-editing to an eventual final draft composition." The teacher believes that the act of "writing takes a lot of time for the students to think and analyze and also writing can be a means for students to discover new ideas during the writing process." She also says that when she gives feedback to her students, "I do not focus on grammar alone, but also on the content of the writing" and that she tries bring in the students themselves (peer editing) to comment and "help one another shape their writing." She 
maintains that writing is a communicative as well as a social act: "One doesn't write for oneself or only for the teacher but to share with other people." She continued, "It is important to show students how the text conforms or does not conform to the readers' expectations."

\section{Chee's Classroom Practices}

Classroom observations (authenticated by Chee) reveal three main issues: classroom interaction, peer-response feedback, and language medium.

\section{Classroom interaction}

One major issue to emerge from the class observations was the teacher's interest in classroom interaction in her writing classes, so much so that there was a marked difference in how the students interacted as the writing classes developed in the cycle of writing a composition. The first class in this writing cycle (pre-writing) began with the teacher standing in front of the students, who were seated in rows, giving an introduction to the writing lesson. The teacher asked individual students questions in lockstep fashion (i.e., the teacher asked a question, and students answered in choral fashion or not at all) until the end of the class. Figure 1 shows the seating chart observation record (SCORE) analysis of the flow of communications during a 15-minute segment (teacher asked all 20 questions), representative in that the teacher asked most of the questions and the students responded with choral or group answers.

After the class, the teacher (who also examined the SCORE segment) noted that the type of interaction that had just occurred was not what she had intended, because she said that she believed that students should interact

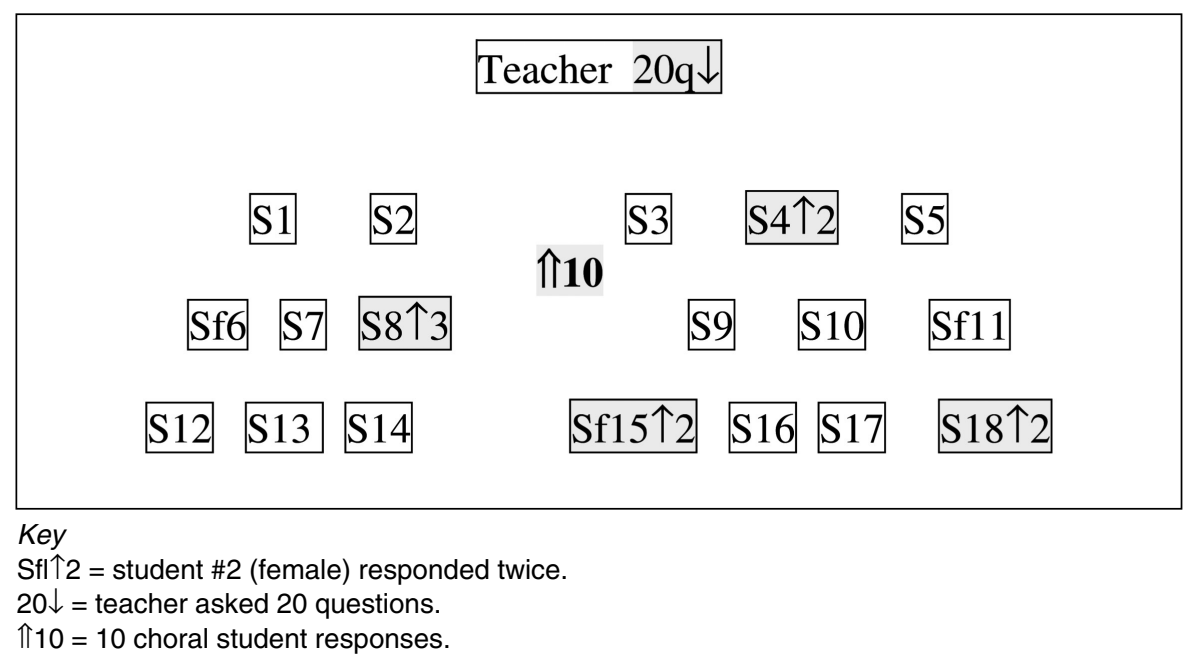

Figure 1. SCORE analysis for interactions in Class 1. 
more with each other during the pre-writing stage in order to generate their own topics for writing. On reflection, she commented that she should have had the students form discussion groups and have each group present the results of these discussions. She continued: "I think this could involve more participation from the students rather than me doing the talking which became monotonous after a short while and there wasn't any analysis of any kind of the results [of the class discussion]."

The teacher not only realized the need for more interaction during the pre-writing stage, but implemented these ideas the next time she started a pre-writing cycle (the seventh classroom observation in our process). She set up discussion groups of students so that they could generate topics for writing, and as a result, the classroom interaction between the students increased dramatically. The teacher realized this change in the classroom interaction: "As I observed the groups working, one group at the back of the class had a lot of interaction and oral discussion and was using English." Figure 2 shows the SCORE analysis of the communication flow in this particular group. In short, the teacher not only reflected on her beliefs in the light of her classroom practices, she also acted on these reflections when she thought there was conflict between her beliefs and classroom practices.

\section{Peer-response feedback}

A second related issue that arose was how the students gave feedback to one another in the peer-response classes. The teacher initiated the peer-response session during the fourth class of the writing cycle, starting the class by asking the students to move into groups to answer questions on peer-re-

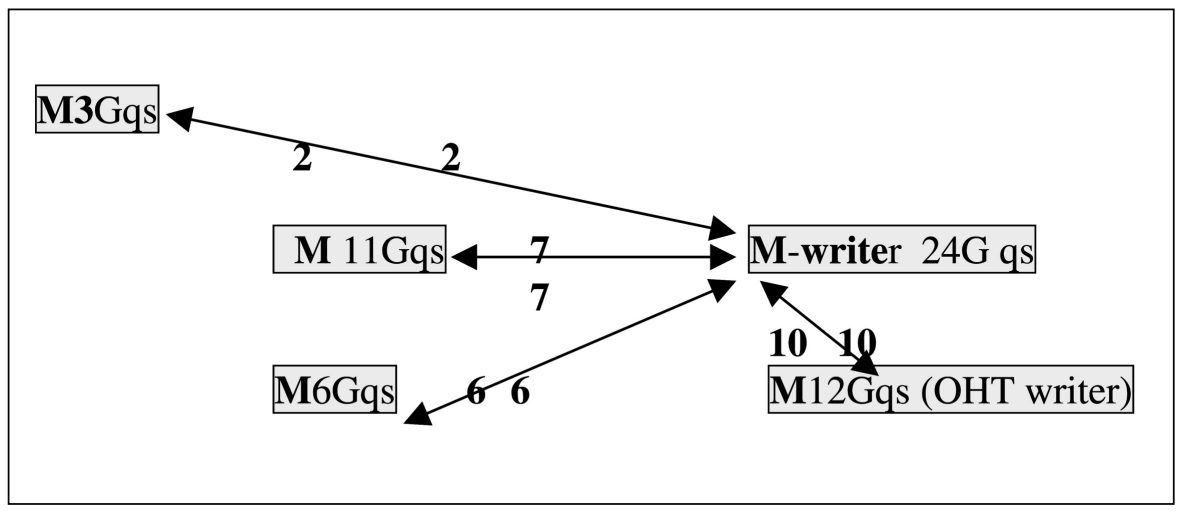

Key

$\mathrm{M}=$ male student.

M3Gqs = male student asks three group questions.

$6+$ asks 6 questions (top of line) and answers 6 questions (bottom of line).

Figure 2. SCORE analysis of Class 7. 
sponse handouts. The students were asked to fill out these handouts (I was not given a copy) to answer questions about their peers' composition. The students sat in groups of four, read compositions, and then wrote at length on the handouts. Next, they exchanged the peer-response handouts and talked to each other in Mandarin (and later, according to the teacher, not necessarily about their writing). The teacher noted after this class that one of her main concerns during the peer-response sessions was not the questions per se that they were supposed to answer; rather, she was concerned that the students seldom talked to each other (or the teacher) about their writing after the response sheets were returned. She remarked that during that class:

I had to constantly remind the students that after reading each other's papers they could discuss and talk about their papers. As from the previous lessons, I noticed that students seldom talk about their essays after reading the feedback given to them by their group members. On my part, I would like them to talk about the essays.

This issue of how to conduct the peer-response classes remained a challenge for her even after this period of reflection, as she could not come to a conclusion about what she expected from the students. She attempted to balance her stated beliefs about the purpose of peer-response classes with her classroom practices. Realizing that her classroom practices were not aligned with her beliefs, she was not afraid to change her practices.

When I asked the teacher in the post-study interview about how she provided feedback to the students, she replied that she gave feedback according to student expectations and also according to which point she wished to emphasize during a class.

I tend to focus more on content and organization. Previously, I tried to correct the errors when I read drafts. Based on feedback from previous students, they would like the teacher to correct their errors. So now I correct them as I spot them in the essays. But I wouldn't spend on a lot of time trying to spot and tediously correct all the errors in their essays.

A later examination of the students' drafts and the teacher's comments on those drafts confirmed that her stated beliefs are reflected in her actions. So a pattern was beginning to emerge in which her beliefs, when she was able to articulate them, would direct her instructional practices.

\section{Language medium}

I noted that many (if not all) the students spoke Mandarin during the classes I observed, and the teacher (of Chinese ethnicity) did not intervene. The teacher noted that she did not require the students to speak in English at all times during the class because they may not have been comfortable doing this. She said that she had adopted this stance only recently (the previous 
year) when she was reading one of her student's journals about being forced to speak only English in class. She continued:

After reading one student's journal [the previous year] who felt he was giving up his Chinese when learning English since all the lessons were conducted in English I had never demanded students to use English in their discussion. So far, during group discussions this had not been comfortable for the students. So I let it be. Reading this [journal] made me realize that learning English could have such an emotional effect on a student. Anyway, even though I had always encouraged students to use English, I had never imposed a ruling in my class that Chinese may not be spoken.

These comments indicate that the teacher has definite beliefs about the language medium in her classroom, and these are evident in her classroom teaching, as I never saw her intervene at any time when the students spoke Mandarin during any of the classes.

\section{Discussion}

The findings suggest that as an experienced EAP teacher, Chee seems to be aware of how learning takes place in her writing classes and she exhibited this by having the necessary courage to change her instruction to reflect what she had intended her students to achieve. Chee was able regulate her classroom actions to match her changing beliefs when she observed that these actions seemed to be at odds with her beliefs. For example, during the sixth classroom observation when she was reviewing the students' first writing draft (she read and commented on each draft), she suddenly started to talk about two grammar items, pronouns and agreement, for the whole class. She lectured about each grammar item by stating the rules, displaying the rules on the overhead projector, and then explaining examples of each. Chee continued:

I moved on to some features of grammar, which I could still detect in student's essays. As I had touched on the ambiguity in the use of pronouns in an earlier lesson, I went through the exercise I showed on the transparency very quickly.

Chee later reflected that she taught grammar overtly only if she thought her students required it, and then only on grammar issues that were relevant to most students. Although this comment seems to be in conflict with her belief that feedback should be focused mostly on ideas and content, rather than grammar, it does not necessarily indicate that she is in divergence with her stated beliefs. Rather, as she had an opportunity to reflect on her teaching, she has also had an opportunity to further clarify her beliefs, showing she is an "expert teacher" (Tsui, 2003) who considers the immediate needs of her 
students. As Tsui has noted, some of the differences between novice and experienced language teachers seem to lie in "the different ways in which they relate to their contexts of work, and hence their conceptions and understanding of teaching, which is developed in these contexts" (p. 245).

However, it also seems that Chee was only able to engage in these reflections by a process of articulating her beliefs about instruction and then comparing them with what she observed (with the aid of a facilitator) was actually taking place in her classes. So from a methodological perspective, the findings of this case study suggest that oral recall and classroom observations may be effective methods for helping language teachers discover the relationship between their beliefs and classroom practices.

It is important for language teachers to do this because the very process of reflecting on and articulating both beliefs and practices of experienced teachers can ultimately help language teachers and teacher educators to recognize what effective teaching is (Batten, 1991). When teachers are encouraged to articulate their beliefs and systematically look at their practice, they can become more confident practitioners, be more flexible about tolerating ambiguity, and become more skillful in communicating about issues related to their work. Moreover, if teachers are encouraged to reflect on their teaching, Batten suggests that they may "enhance their own teaching, and establish a basis for sharing their knowledge with other teachers through school-based professional development" (p. 295). It is also important to note that in order to engage in reflective practice, teachers need a sense of security. Therefore, it is important that trust be built between the facilitator and the teacher, enabling both to communicate without fear (Farrell, 2004). As facilitator, I assured Chee that I would keep confidential any findings and would not publish any of the findings she had not wished made public. I assured her that I would act as a "mirror" so that I could reflect back to her an image of her practice. I suggest that to be truly useful and nonthreatening, my job was not to provide expertise, but to create an environment that supports reflection. I took the position that I would not give any advice unless I was asked for it-I was not asked.

Consequently, of course, one criticism of the above case study could be that the teacher was not challenged when her beliefs conflicted with her classroom practices. In fact, Chee was able to challenge herself in these instances. This may also prove the case for many other experienced language teachers who need only time and space to separate them from the event.

In addition, the findings of this study seem to agree with those of earlier studies that caution against placing teachers of writing (or any other skill area) into predefined categories such as a "process writing teacher" (Katz, 1996; Shi \& Cumming, 1995; Woods, 1996). As Katz suggests, these methodological concepts do not really tell us anything about what teachers do, and so she maintains that "reflecting on teaching styles will lead to a fuller 
understanding of the teaching situation" (p. 85). Specifically related to teachers of second-language writing, Brock (1994) has observed that teachers in the Asia-Pacific region have their own attitudes about what effective teaching of writing is, and that "these attitudes have been shaped by experience, society, and the educational culture in which the teacher works" (p. 51). The findings from this case study suggest that is also the case for Chee, as she seems to have conceptualized her teaching of academic writing in her "own way by a combination of a process approach adapted to the learning context of the students with a focus on the product when necessary." She continued further on how she organized her lessons.

Some activities are student-centered. For example, group-work in peer-review, drafting, or times when students work on the computer. However, sometimes the activities are teacher-centered when I feel I need to address some common problems in students' writing. Anyway, I feel I tend to control what's going on in the classroom.

As Shi and Cumming (1995) also discovered, teaching is a highly personalized and individual matter. No two teachers teach in the same way, even when they may have had similar training.

\section{Conclusion}

The case study reports in detail how Chee reflected on and interpreted her approach to teaching academic writing in her context (Singapore) to students from the People's Republic of China. Chee has clearly shown that she has a repertoire of teaching strategies and techniques for teaching academic writing that she can and does use. By a process of articulating her beliefs (to herself as well as to a facilitator) about teaching academic writing, and then by considering how these beliefs affected her classroom practices, the teacher was able to "critically reflect on the wisdom of her practice" (Shulman, 1987, p. 11).

The point of reflective practice as outlined in this article was not to prescribe specific "correct" beliefs and practices, but rather to encourage language teachers to become more aware of their beliefs and practices so that any gaps that may exist between the two could be examined. In this way, teachers can begin the process of uncovering their assumptions about teaching EAP writing. Ultimately, individual teachers must decide whether to change any of their beliefs, whether to incorporate other beliefs into their practice, and whether to change their practices.

\section{The Author}

Thomas S.C. Farrell is an associate professor in applied linguistics at Brock University. He has written extensively on topics such as reflective practice, language teacher development, and language teacher education. His recent books include Reflective Practice in Action (2004, Corwin 
Press), Reflecting on Classroom Communication in Asia (2004, Longman), and Professional Development for Language Teachers (2005, Cambridge University Press, coauthored with Jack Richards).

\section{References}

Batten, M. (1991). Identification and development of teachers' professional craft knowledge. In Ho Wah Kam \& Ruth Wong Y.L. (Eds.), Improving the quality of the teaching profession: An international perspective (pp. 295-305). Singapore: Institute of Education.

Bogdan, R., \& Biklen, S.K. (1982). Qualitative research for education: an introduction to theory and methods. Boston, MA: Allyn and Bacon.

Borg, S. (1998). Teachers' pedagogical systems and grammar teaching: A qualitative study. TESOL Quarterly, 32, 9-38.

Borg, S. (2003). Teacher cognition in language teaching: A review of research on what language teachers think, know, believe, and do. Language Teaching, 36, 81-109.

Brock, M.N. (1994). Reflections on change: mplementing the process approach in Hong Kong. RELC Journal, 25(2), 51-70.

Burns, A. (1992). Teacher beliefs and their influence on classroom practice. Prospect, 7(3), 56-65.

Cruickshank, D., \& Applegate, J. (1981). Reflective teaching as a strategy for teacher growth. Educational Leadership, 38, 553-554.

Day, R. (1990). Teacher observation in second language teacher education. In J.C. Richards \& D. Nunan (Eds.), Second language teacher education (pp. 43-61). Cambridge, UK: Cambridge University Press.

Farrell, T.S.C. (2004). Reflective practice in action. Thousand Oaks, CA: Corwin Press.

Gaies, S. (1991). ELT in the 1990s. JALT Journal, 13(1), 7-21.

Glesne, C., \& Peshkin, A. (1992). Becoming qualitative researchers: An introduction. New York: Longman.

Golombek, P.R. (1998) A study of language teachers' personal practical knowledge. TESOL Quarterly, 32, 447-464.

Johnson, K.E. (1990). The theoretical orientation and instructional practices of a pre-service English as a second language teacher. In J. Gantzer (Ed.), Issues and innovations in ESL teaching and learning: Selected papers from New York State TESOL '88-'89 (pp. 3-14). New York: TESOL.

Johnson, K.E. (1992). Learning to teach: Instructional actions and decisions of preservice ESL teachers. TESOL Quarterly, 26, 507-535.

Johnson, K.E. (1994). The emerging beliefs and instructional practices of preservice English as a second language teachers. Teaching and Teacher Education, 10, 439-452

Johnson, K.E. (1999). Understanding language teaching: Reasoning in action. Boston, MA: Heinle \& Heinle.

Kagan, D.M. (1992). Implications of research on teacher belief. Educational Psychologist, 27, 65-90.

Katz, A. (1996). Teaching style: A way to understand instruction in language classrooms. In K. Bailey \& D. Nunan (Eds), Voices from the language classroom (pp. 57-87). New York: Cambridge University Press.

Lee, I. (1998). Writing in the Hong Kong secondary classroom: Teachers' beliefs and practices. Hong Kong Journal of Applied Linguistics, 3(1), 61-76.

Lincoln, Y.S., \& Guba, E.G. (1985). Naturalistic inquiry. Beverly Hills, CA: Sage.

Lowych, J. (1986). Post-interactive reflections of teachers: A critical appraisal. In M. Ben-Perez, R. Bromme, \& R. Halkes (Eds.), Advances of research on teacher thinking (pp. 172-185). Berwyn, PA: Swets

Nieto, S., Gordon, S., \& Yearwood, J. (2002). Teachers' experiences in a critical inquiry group: A conversation in three voices. Teaching Education, 13, 341-355. 
Pennington, M.C., Costa, V., So, S., Shing, J. Hirose, K., \& Niedzielski, K. (1997). The teaching of English-as-a-second-language writing in the Asia-Pacific Region: A cross-country comparison. RELC Journal, 28, 120-143.

Richards, J.C. (1994). The sources of language teachers' instructional decisions. Research report No. 38. Hong Kong: City Polytechnic of Hong Kong, Department of English.

Richards, J.C., \& Farrell, T.S.C. (2005). Professional development for language teachers. New York: Cambridge University Press.

Richards, J.C., \& Lockhart, C. (1994). Reflective teaching. New York: Cambridge University Press.

Shi, L., \& Cumming, A. (1995). Teachers' conceptions of second-language writing instruction: Five case studies. Journal of Second Language Writing, 4, 87-111.

Shulman, L. (1987). Knowledge and teaching: Foundations of the new reform. Harvard Educational Review, 57, 1-22.

Stake, R. (1995). The art of case study research. Beverly Hills, CA: Sage.

Tsui, A. (2003). Understanding expertise in teaching: Case studies of ESL teachers. New York: Cambridge University Press.

Valli, L. (1997). Listening to other voices: A description of teacher reflection in the United States. Peabody Journal of Education, 72(1), 67-88.

Wallace, M. (1998). Action research for language teachers. Cambridge, UK: Cambridge University Press.

Woods, D. (1996). Teacher cognition in language teaching. New York: Cambridge University Press. 